\title{
Psychological experiences of refugees and the response of the community in the Lake Chad region
}

\begin{abstract}
In recent years, the Lake Chad region which is an intersection of four countries, namely; Cameroon, Chad, Nigeria and Niger, has been a major battleground of insurgency and political instability. Particularly, the emergence of Boko Haram and the devastating impact of its activities, exposed the vulnerability in the region. Poverty is prevalent in the region - a situation which has been argued as one of the factor accounting for successful operation of Boko Haram. In the midst of less economic activities, it is important to understand the psychological impact of insurgency on the lives of individuals who have moved from their indigenous homeland to resettle in new communities. Sixty-seven participants were interviewed from nine communities in Cameroon and Nigeria. Participants were psychologically affected by their losses; relatives, properties and even displacement from their homelands. Also, the limited economic activities in the region manifested in the inability of the people to have access to income generation activities. Notwithstanding, the host communities provided solace to the participants by accepting them as equal members of the society and integration in the communities. Most importantly, they see them as their brothers and sisters who have been displaced from their respective communities because of attacks from Boko Haram. The study has implication for policy-making, in terms of governments and international partners, exploring ways to create economic opportunities to advance the lives of refugees and internally displace persons (IDPs) in the region.
\end{abstract}

Keywords: Lake Chad region, refugees, poverty, employment

\section{Introduction}

The high rate of terrorism and political violence has led to an increase in the number of refugees globally (UNHCR, 2015, 2014). These developments influenced international legislations and conventions which guarantee refugees the right to protection. Specifically, the principle of non-refoulement of the 1951 Refugee Convention endeavour countries to offer protection to individuals who are escaping persecution as a result of their race, religion, ethnicity and nationality (Feller, Khan, Jacquemet \& Lecler, 2001; Jaeger, 2001). However, there is tension in the literature regarding who a genuine refugee is, since there are others, branded as economic migrants who aspire or have left their countries in search of greener pastures. These perceptions of refugees fleeing to look for economic opportunities might raise concerns in the host country which could have impact on their integration and psychological 
well-being. Consequently, some countries such as members of the European Union, United States and Australia have resorted to institutionalising strict immigration policies which are in conflict with international conventions. For example, these developments apparently divided European Union on the formula to use to distribute refugees, mostly from Middle East, subSaharan Africa and South Eastern Asia, who flooded Europe in 2015. It is not always the case that refugees from low-income countries would seek asylum in advanced countries - some would cross the border to resettle in a neighbouring country. This seems to be the situation in Nigeria and its northern neighbours who have had their fair share of terrorists' attacks which gained international spotlights due to high death tolls and displacements. It is therefore important to examine the experiences of refugees who have survived terrorist attacks and sought protection in an area where there is limited income generation activities.

The Lake Chad region, which is an intersection of four countries - Cameroon, Chad, Nigeria and Niger, has been plagued with ethnic conflicts over natural resources use and allocations (Angerbrandt, 2017; Okpara, Stringer, Dougill \& Bila, 2015). Access to land for farming and river for fishing has become a critical issue as ethnic groups arm themselves to fight for control and protection of their resources (Onuoha, 2008; Oyewole, 2015). Interestingly, none of the countries has resorted to diplomatic measures to resolve the conflicts regarding management of natural resources in the region. Although farming is a major activity in the region, the individual countries unilaterally constructed dams in their share of Lake Chad Basin which has affected flow of the water - impeding farming activities (Coe \& Foley, 2001; Okpara et al., 2015). Water shortage has seen people crossing into other countries in search for fertile lands for agriculture (Coe \& Foley, 2001; Ngatcha, 2009). This development has contributed to ethnic and communal clashes which have led to the death of many people. Moreover, these developments have impacted on livelihoods of people which have resulted in high rate of poverty in the region. additionally, nefarious and illegal activities such as drug 
abuses, human and arms trafficking is on the rise in the region because of the limited economic activities and the failure of countries to come to a consensus on the collective interests of people living in the area (Angerbrandt, 2017; Neiland \& Bene, 2003; Oyewole, 2015). The peculiar situation in the Lake Chad region has made it fertile for criminal groups, as happened in the case of Boko Haram, to exploit the chaotic situation to their advantage.

The emergence of Boko Haram is not only an indictment on the Nigerian security services but also exposure of the vulnerability in the Lake Chad region which has received little publicity for decades. In some quarters, it has been argued that the lax borders in the region helped to expand the life span of Boko Haram who successfully operated in all four countries (Comolli, 2015; Weeraratne, 2017). The Islamic fundamentalist group emerged in NorthernEastern Nigeria and started preaching against injustice and deplorable living conditions of people in the region. Boko Haram preached against Western education which according to them, has made some people rich while the masses lived in abject poverty (Akinola, 2015). One of the targets in all the four countries was destruction of school buildings which they perceived as instrument of oppression of the poor (Oyewole, 2015). They enjoyed the support of the poor in the region whom they provided with services that the government of Nigeria could not give them. Underestimation, poor intelligence and wrong approaches, have been cited as major reasons the Nigerian government could not defeat Boko Haram on its soil (Akinola, 2015; Comolli, 2015; Weeraratne, 2017). By succeeding in their native Nigeria, Boko Haram extended their activities to the Lake Chad region (Akinola, 2015; Gray \& Adeakin, 2015). The Lake Chad region became an easy run for Boko Haram as a result of deep seated ethnic conflicts mainly due to scarcity of natural resources and limited economic activities.

The devastating impacts of the activities of Boko Haram extend beyond the borders of Nigeria into neighbouring countries in the Lake Chad region. For example, huge death tolls, loss of properties and disruption of economic activities has been explored (Hansen, 2017; 
Mbah, Mwangwu \& Ede, 2017; Opoku, Sakah \& Alupo, 2017; Popovski \& Maiangwa, 2016; Weeraratne, 2017). At some point, they were described as the most dangerous terrorist group in the world due to the rate at which they killed people in the region (Institute for Economics and Peace, 2015). Initially, Boko Haram was seen as a Nigerian problem as the neighbouring countries failed to act when the Nigerian government called for their support (Oyewole, 2015). At some point, the Nigerian government had issues with Cameroonian and Chadian authorities who were accused of protecting Boko Haram forces (Oyewole, 2015; Weeraratne, 2017). However, the situation changed when Boko Haram began to stage attacks in all four countries in the Lake Chad region. Consequently, the governments saw the essence of pooling military resources together to defeat the group.

While much is known about the destructions caused by Boko Haram in the Lake Chad region, little is known about the life of displaced persons. Beyond international condemnations of atrocities and massacres, the psychological impact of the insurgency on survivors in the Lake Chad region is yet to be explored. There is humanitarian crisis in the Lake Chad region due to rising number of refugees whose needs have not been prioritised in international discourses (Mercy Corps, 2017; Oyewole, 2015). In the midst of less economic activities in the Lake Chad region, there is an urgent need to understand the psychological impact of insurgency on the lives of refugees who have moved from their homeland to resettle in new communities. Using a qualitative method of data collection, this study documented the psychological impact of terrorism and communal response to resettlement of refugees in the Lake Chad region. For the purpose of this study, psychological stress is defined as consequences of exposure to war or terrorism. Also, refugees and internal displaced persons (IDPs) will be used interchangeably because of the complexity in the area and ease of movement of people that has made it difficult to distinguish between the two concepts in the region. Due to lack of proper identification systems, people in the Lake Chad region choose to belong to any country at a point in time. 
Thence, a refugee in one country was once a native and they have returned to resettle. Similarly, an IDP emigrated from a community which is in another country to resettle at where they have been displaced.

\section{Experiences of Refugees and its psychosocial impacts}

Stable societies are firmly grounded on safety, social bonds, justice as well as identities and coherence (Silove, Ventevogel \& Rees, 2017). These foundations are likely to be affected in the event of war because of destructions which could affect agencies that keep people together. Inevitably, attention has to be paid to supporting refugees to regain what they have lost rather than generalization of interventions to refugees (Bogic et al., 2012, 2015). Conceptually, this has contributed to the emergence of eco-social system model which argues that interventions ought to be tailored to suit a specific context (Silove et al. 2017). There exist remarkable disparities in the experiences of refugees and as such, it has been recommended that supports are contextualised to suit their diverse needs (Georgiadou, Morawa \& Crim, 2017). The complexity surrounding conflicts in the Lake Chad region presuppose that humanitarian services would be geared towards addressing the basic needs of people who have been rendered homeless or destitute.

Many refugees go through three transition phases in which each of them have impact on their psychosocial well-being. Different challenges are encountered during the war, in flight and arrival at new communities (Guajardo, Slwea-Youran, Santalucia \& Jorm, 2016; Hirani, Payne, Mutah \& Cherian, 2015; Lincoln et al. 2016; Rask et al. 2016; Shawyer et al. 2017). Basically, refugees may be psychologically affected since most of them might have lost properties, family and livelihoods (Abbott, 2016; Bogic et al. 2015; Holmes et al. 2017; Valibhoy, Szwarc \& Kaplan, 2017). Some refugees might witness the murder of their family members and neighbours which connote the need for consideration to be given to their cognitive recovery (Lincoln et al. 2016). Perhaps, the activities of Boko Haram have caused 
further movements as a result of deaths and forced migration in the Lake Chad region where there have existed historical battles for land and movements.

Surviving war is not the end of the struggle for refugees, as sometimes they have to embark on difficult journeys to reach new environments. The most common challenges faced by refugees before leaving their homelands could be lack of employment because of destruction of properties and source of livelihoods (Abbott, 2016; Seguin et al. 2016; Silove et al. 2017). Consequently, they left war torn zones in search of better life; however, their inability to get what they expect may have adverse effects on their mental well-being (Akua-Sakyiwa, 2017). According to Myhrvold \& Småstuen (2017), refugees encounter uncertainties, in terms of job acquisition and being granted permanent stay in their new communities. Their inability to have a stable life and fear of deportation to their homeland is a source of psychological stress. Almost all these studies were conducted in advanced countries where there existed infrastructure and laid down programmes to support the integration of refugees. In the Lake Chad region, there is a possibility of frustrations in search of stable life; in an area where there has been limited economic activities. Before the advent of Boko Haram in the Lake Chad region, there existed high rate of poverty, unemployment and lack of basic amenities (Okpara et al., 2015; Oyewole, 2015). It will be interesting to ascertain the daily living conditions of refugees who have been displaced in this volatile region.

Similarly, there is a possibility of refugees having different culture compared to the environment they find themselves (Ager \& Strand, 2008; Hirani et al. 2015; Rask et al. 2016; Reinelt, Vasileva \& Petermann, 2016; Wright et al. 2016). In view of this, moving to a new environment means that they have to adapt to a new way of life. In some cases, refugees from conservative cultural and religious societies find it difficult to adapt - a situation which affects their psychological well-being (Basheti, Quinaibi \& Malas, 2015; Schick et al. 2016). Guajardo et al., (2016), reported that educational programmes and cultural orientations are critical as 
they enable refugees to understand life in their new communities. Since there is already a shared identity between the people in the Lake Chad, there is no need institutionalising such programmes. Notwithstanding, the literature is yet to pay attention to the psychological welfare of refugees displaced and relocated to neighbouring country, as pertains to the case in the Lake Chad region. Also, the literature is yet to explore the psychological experiences of refugees displaced by insurgency in the Lake Chad region. Perhaps, refugees may have different experiences which could be informative and provide in-depth understanding of the life of displaced persons in the Lake Chad region. This study aim to fill this scholarly gap and assess the experiences of refugees in Lake Chad region who have to contend with losses and relocated to environment they are familiar with and could identify themselves with the communities.

\section{Methods}

\section{Study participants}

This exploratory study used interviews and focus group discussions to collect data. A total of 67 participants were conveniently recruited from nine communities, that is, four in Cameroon and five in Nigeria. Because of shared borders of the four countries, people can cross to the other country with ease. Since we notified security officers in control of the areas about this study, they advised us not to cross to communities in Chad and Niger because of instability and pockets of violence. Due to this, we decided to collect data from only Cameroon and Nigeria. The population of this study included refugees, IDPs, community/opinion leaders as well as other humanitarian agencies involved in supporting refugees in Lake Chad Countries. The data was collected in November 2016, using an interview guide developed based on review of literature. We began the data collection in Cameroon before crossing the border to Nigeria. In all, we spent six weeks in the field and only moved based on recommendations from security officers. 


\section{Data collection procedure and management}

We sought the approval of relevant authorities before field work was carried out. In the first place, the study and its protocols were approved by Pan African University, Insitute of Governance, Humanities and Social Sciences, Cameroon. Also due to security implication of the study, the following ministries and authorities were informed about the study; in Cameroon, the Ministry of Territorial Administration and Decentralization in Yaoundé, the Office of Governor of the Far North Region of Cameroon, Maroua; the Divisional Head of Mokolo, the Lamido of Zamay and in Nigeria, State National Emergency Management Agency in charge of IDPs in the North-Eastern region was informed before data collection.

After relevant authorities had been informed about the study, a formal letter was given to us to be given to the camp managers to allow us to collect data from the victims. We received an orientation about the management of camps and taken on tour by the managers. The managers used a public address system to inform the people about the study and invited some of them to volunteer to take part in the study. The heads of security at the camps determined the nature of data collection. In Cameroon, the head of security allowed us to conduct focus group discussions in both camps and in Nigeria; we were not allowed to conduct focus group discussion for security reasons. Twenty-eight participants, shared between 13 and 15 participants, took part in the two focus group discussions conducted in Cameroon while the rest (39) participated in the study through one-on-one interviews.

In the communities, copies of the letter of introduction were given to the host community leaders who led us to the home of refugees who have resettled in the communities. Due to language barrier, an interpreter was hired to help us in the data collection. The interpreter informed the participants about the study; its objectives and assured them that their identity would not be disclosed to any third party or in the reporting of the study. The discussions during interactions were audio-recorded, and those who agreed to participate in the 
study signed or thumb-printed on the informed consent forms. The participants were informed of the risk of participation which is a reminiscence of experiences and loss of loved ones. This prepared their minds and they passionately shared their stories.

\section{Data analysis}

We followed Braun and Clarke (2006) on four-step process of thematic analysis of qualitative data. The stages are as follows; coding, theme identification, theme organisation and description. The audio-recorded interviews were professionally transcribed verbatim into English from four languages (French, Fulfulde, Kanuri and Hausa) used in the data collection. The transcribed audio-interviews were listened to several times to ensure accuracy. We read the transcribed audio and text several times to observe if there was any difference. There were priori themes that was developed during literature and interview guide. These themes were compared with the themes that emerged from reading of the transcriptions. Afterward, the themes were organised according to the participant groups (IDPs, refugee and host communities' leaders and humanitarian agencies) in order to observe any differences in the experiences of the participants. The last stage was description of the themes according to which data were interpreted.

\section{Results}

\section{Demographic characteristics}

Thirty-one (46\%) participants were recruited from Cameroon while $36(54 \%)$ were from Nigeria. Two focus group discussions made up of six and 12 members were conducted in Cameroon. The rest of the participants were engaged in one-on-one interview discussions. Twenty-nine (43\%) of the participants were IDPs while five (7\%) were camp managers. Fortyone $(61 \%)$ of the participants were females while $26(39 \%)$ were males. In terms of nationality, 28 were Nigerians while nine were from Niger. About education, 23 (34\%) had no formal 
education compared to eight (12\%) who had university qualification; 21 (31\%) were between 51-60 years, and 34 (51\%) were Muslims (see Table 1 for details).

Table 1: Demographic characteristics of participants

\begin{tabular}{|c|c|c|}
\hline \multirow{2}{*}{\multicolumn{3}{|c|}{$\frac{(\mathrm{N}=67)}{\text { Participants }}$}} \\
\hline & & \\
\hline Refugees & 25 & 37 \\
\hline IDPs & 29 & 43 \\
\hline Host community leaders & 8 & 12 \\
\hline Camp managers & 5 & 7 \\
\hline \multicolumn{3}{|l|}{ Number from each country } \\
\hline Cameroon & 31 & 46 \\
\hline Nigeria & 36 & 54 \\
\hline \multicolumn{3}{|l|}{ Gender } \\
\hline Female & 41 & 61 \\
\hline Male & 26 & 39 \\
\hline \multicolumn{3}{|l|}{ Nationality } \\
\hline Cameroon & 16 & 2 \\
\hline Chad & 13 & 19 \\
\hline Niger & 9 & 13 \\
\hline Nigeria & 28 & 42 \\
\hline \multicolumn{3}{|l|}{ Education } \\
\hline No education & 23 & 34 \\
\hline Primary & 17 & 25 \\
\hline Secondary & 19 & 28 \\
\hline University level & 8 & 12 \\
\hline \multicolumn{3}{|l|}{ Age } \\
\hline $21-30$ & 9 & 13 \\
\hline $31-40$ & 19 & 28 \\
\hline $41-50$ & 4 & 6 \\
\hline $51-60$ & 21 & 31 \\
\hline $61-70$ & 4 & 6 \\
\hline $71-80$ & 7 & 10 \\
\hline $81-90$ & 3 & 4 \\
\hline \multicolumn{3}{|l|}{ Religion } \\
\hline Christianity & 13 & 19 \\
\hline Muslims & 34 & 51 \\
\hline Traditionalists & 2 & 3 \\
\hline None & 18 & 27 \\
\hline
\end{tabular}

\section{Experiences and psychological impacts}

The participants were asked to recount their encounter with Boko Haram and how they feel whenever they recall their experiences. Almost all the participants interviewed responded that 
they feel traumatized whenever they remember what happened to them. They attested losing their friends, families and even properties they have labored for all their lives.

I will narrate the story to my great grandchildren that Boko Haram insurgency destroyed people's lives including myself; our people were killed; our wealth is no more there, a whole community like ours has become empty; there is nothing left and it has now become bushy. I lost 38 relatives killed but could burry only (IDPs, 8, Yola, Nigeria)

Ah, of course! Certain things man will only forget after his death because it is something you never think it can happen. I have a problem; it does come to me like a dream or something strikes my head due to the encounter with Boko Haram in Madagali (IDPs 2, Yola, Nigeria)

Whenever I think about the incidence, what comes to my mind is a number of houses that were burnt, a number of friends that were killed; it doesn't give me any desire of going back. (IDPs, 5, Mokolo, Cameroon)

The memories of the past, in terms of loss of lives and properties, had impact on the psychological well-being of participants. Some participants mentioned that they do not want to go back to their communities due to the nostalgic moments they had. They lost everything and going back would remind them of the past. The following quotations summarise their experiences;

Even now, I am yet to recover from the traumatized experience caused by the loss of my husband and two children to Boko Haram. I am not thinking of going back there except I want to kill myself. The memory is still there, going back may imply that I am planning to live in sorrow for the rest of my life (IDPs 23 from Bama, Nigeria)

If at all peace has been restored in my community, I don't think I will go back, all my houses have been burnt; I don't have anything there anymore (IDP 17; Mokolo, Cameroon)

I do not think of returning to the community where I was once wealthy but now with nothing. Seeing our family houses and my businesses destroyed and my friends and relatives killed in the same place, I cannot go back to see these things; it may add to my unpleasant experience (IDP 8, Yola, Nigeria)

\section{State of refugees and its impacts}

Participants were led to discuss the impact of their present condition on their psychological well-being. It came out during interactions that some participants have lost everything they labored for in life which usually gives them psychological stress. Most 
participants discussed that the conditions in which they found themselves have affected their psyche since they were better off before their communities were attacked.

We are struggling with life here in our camp; I don't feel well when I think about the past but government has been taking care of me; they give us food, medicine and give us advices every time to take the occurrence as the will of God" (IDPs 13, Yola, Nigeria).

We have been living without food supplies for three months; we have now become beggars while many of us fed ourselves and other relatives before Boko Haram drove us out of our communities. This situation always reminds us of what we have lost to Boko Haram, and feel traumatized (Focus group 2, Zamay, Cameroon)

The change of status of refugees, from breadwinners to dependence on other societies was source of stress. They have fled their wealth or lost it and had to wait on others before having something to eat on a daily basis. The situation has not only affected the refugees but the camp managers and communities' members who were unable to do much to enhance their living conditions.

It is difficult to take care of all the refugees and I feel discomforted whenever there is no money to buy what they need for subsistence. It gives me headache because I often become restless and sleepless (Community leader, Zamay, Cameroon).

We sometimes can't help the situation! They [refugees] depend on limited health care, clothing and food items at our disposal. At the end of the day, we find ourselves being extremely anxious and nervous; we won't be able to eat due to the stress involved in meeting the demands of the refugees (Camp Manager, Minawao)

Some participants did not want to go to the camp because they would not want to be seen as beggars as they prefer to look for avenues to support themselves. While some were successful, others could not find anything worthwhile. One participant said, "Being at the camp means that you don't have anyone or a beggar. I have friends here already so I decided to rely on them to settle here."

\section{Needs of participants}

Participants recounted the absence of basic facilities in their new communities and camps.

Several issues were raised but the most common ones were lack of schools, food and 
healthcare. Most mentioned that the absence of these basic necessities have had impact on their lives. Those who had children could not send their children to school because there were no schools in the camps as well as lack of school facilities in the communities. One participant said that "there are no schools for our children here in the camps. We only gather them to play together and know one another. Their parents are not happy so we are working hard to keep the children active" (Camp manager Damare, 3). In terms of access to healthcare, there were reactions; while some claimed they have been treated, others said they did not have access to healthcare. In fact, some participants who lived outside the camps mentioned that they were refused medical care when they went to health facilities due to their inability to produce an identification document when requested.

We are trying our best to support them anytime they report at the camps. Some are shot but they manage to run and get here. We have a small clinic here where they are given first aid. We have medical doctors that are coming here. However, we refer conditions we can't handle to the main hospital or we call them to come and help us. (Nigeria Government Agency, Yola)

It is quite hard for us to access medical services at the state-owned hospital as they always ask for our documents and we don't have any. These documents were burnt down alongside our properties when Boko Haram attacked our communities in Maiduguri (Refugees 2 from Mokolo, Cameroon)

I have injuries but no one cares to take care of me. I am disturbed about the experience every day of my life but there is no hospital here in this community so I have to rely on herbal medicine. People in the community have been providing some (herbs) for us to get well (IDPs 16 from Gombi, Nigeria)

Participants discussed the interventions they need to enable them adjust to life in their new communities. The most widely mentioned need was jobs which would keep them busy to overcome their psychological problems as well as enabling them to live independently. One camp manager mentioned, "Without jobs, they continue to think about the past; what they have lost and what they don't have now" (Camp manager 3 Damare, Nigeria). Another community leader added, "They could feed themselves when they are working."(Community leader 5, 
Mokolo, Cameroon). It emerged that some participants left the camp to start a new life which has never materialized because of limited opportunities. Some participants detailed as follows:

You know what we need first - ability to feed ourselves! I don't have anything to do here. So, I can't feed myself. This often causes me to think about my encounter with Boko Haram and what I passed through. It makes everything around me irritating. I need a job that can feed me and my family to get out of this mess (IDP 17 from Minawao, Cameroon)

My idleness poses me the greatest challenge. I can't think clearly and logically because there is no financial resource to support my plans. I need to engage in economic activities in order to get out of my current state. I have no idea on how to go about it for now (IDP 22 from Yola, Nigeria).

Some participants reiterated that they have received vocational training from humanitarian agencies but there are no funds for them to start their businesses.

I have learned how to make shoes at the camp but I have no startup capital till now. The cooperative banks I have approached have many requirements, including identity card and guarantors, before they can offer a loan. It is difficult to meet these requirements as a refugee (Refugees 18 from Maroua, Cameroon).

Although I was a tailor before now, I have received more training at the camp but I have not opened a shop. I have received promises from the trainers and governments' representatives but nothing is coming forth from both sides.

\section{Communal support to refugees}

The study found that participants were united to end bloodshed by Boko Haram and their fighters. There was consensus among participants that Boko Haram did not discriminate as they attack any community they want to attack. This has made the people realize the need for them to contribute their quota towards lasting peace and security in the communities. One community leader said, "We are all at risk as they can hire people to attack their communities. Now we want peace in the communities so that they could go back and work" (Community Leader 6, Yola, Nigeria). Another participant said, "They hired my son because he wasn't working to attack and kill people. We have formed volunteers to protect this community" (Refugee 5, Mokolo, Cameroon). Similarly, a camp manager mentioned, "This is not the ideal 
place for them and they hope that there will be peace in their homes for them to go back" (Camp manager 3, Damare, Nigeria).

Participants shared their thoughts on how the refugees are being supported to resettle in the communities. The communities have formed neighborhood watch committees who visited the camps and individuals who have resettled in the community on daily basis to chat with them. Also, they do encourage members of the community to invite them to their homes or work places in order to keep them active.

As you can see, we don't have much to offer but we do our best to visit and talk to them daily. There are people who go to the camps and homes to spend time with them. That would help them and even smile (Community leader 5, Mokolo, Cameroon).

The elders here (community) come around and interact with people here. They also bring children to play football and entertain the people here. At least, they have realized that the community is care (Camp Manager, Minawao).

Similarly, a significant number of the refugees acknowledged that they were well received by their host communities. The community has taken it as a responsibility to support their tribesmen who have escaped from insecure communities which were besieged by Boko Haram. Some participants confirmed that they have been supported to start an economic activity and given housing to live in the communities. Similar, those in the camps confirmed receiving food supplies from people within the communities.

We have issues handling them here but the local people have stepped in to support us to take care of them. In fact, they are brothers, sharing same borders, culture and language. One thing I'm happy about is that they don't discriminate. The communities have received those displaced persons from the same country (Cameroonians) and they have also received displaced persons from Nigeria (Camp Manager 2, Maroua, Cameroon).

In terms of social cohesion, they never encounter a lot of problem in addressing the issues; the host community has done a lot to host them. There is no need for separation whether the IDPs are from Nigeria or Cameroon. They were well received by the community as a whole. Some of them share the little they have together. (Camp Manager 1, Maroua, Cameroon) 
The community has received me with two hands. They support us to forget about what has happened and stay with them. We speak the same language and you can't differentiate between Nigerian and Cameroonian. They are supporting us to start a new life here (IDP 3, Mokolo, Cameroon)

The community has stepped in to support the brothers and sisters to overcome their miseries and resettle.

\section{Discussion}

This study sought to examine terrorism and its psychological impacts on the lives of refugees in the Lake Chad region. This study was conducted using eco-social model which makes a case for contextualizing mental health service delivery (Silove et al., 2017), as a lenses. Boko Haram managed to stage rampant attacks at the intersection of four different countries which, according to Mercy Corps (2017) and Oyewole (2015), has resulted in massive humanitarian crisis in an area already bedeviled with challenges. Although many scholars have commented on poor management and approach by the Nigerian government towards Boko Haram (Hansen, 2017; Oyewole, 2015), the same could be extended to its neighbours who failed to act in time. The countries in the Lake Chad region share many unapproved routes between each other and it is somehow curious the inaction and late response of governments to battle Boko Haram on their territories (Oyewole, 2015). In the heat of Boko Haram attacks in the Nigerian territory, none of the governments were prepared to deploy military to patrol its borders to enable the Nigerian government contain the group within its borders. This seems to suggest the existence of cold tension between countries which apparently played to the advantage of Boko Haram and its fighters, who were able to have foothold in the area, before international pressure culminated in joint military action by the four countries to fight Boko Haram.

The complexity in the Lake Chad region has been unattended to for many years by all governments as they have failed collectively, to share ideas on best way to improve the living 
conditions of people in the area. Rather, as reported by Okpara et al., (2015), they have worsened the conditions of the people who are mainly farmers with the unilateral construction of dams without recourse to its ramification on livelihoods. The action to construct dams has affected farm activities as the flow of water have reduced and hence, keeping people out of income generating activities. The few fertile lands were being fought for by various factions in the communities - rending the region unstable and prone to external attacks (Ngatcha, 2009; Okpara et al., 2015). Without any means of livelihood and internal struggle between communities, it is understandable the ease with which Boko Haram was able to stage attacks in all four countries. In the absence of unity among the people in the region, Boko Haram managed to infiltrate their ranks by even recruiting their own people to perpetrate violence within their own communities. Admittedly, Boko Haram rekindled a problem which has existed for years, and as found by this study, the participants seem to have realised that their common enemy is Boko Haram fighters who have altered the living and settlements in the region. Although there existed tension between various ethnic groups within the region which revolved around search for a means of livelihood, the emergence of Boko Haram seems to have informed the people the need for them to stay united.

Boko Haram capitalised on shared culture and porous borders to operate and inflict pain on participants. As reported by participants, they have lost their family, children, farms and relatives which continue to haunt them. This is unsurprising because the pillar of every community is the ability of people to share family, own properties and build networks (Silove et al., 2017). Boko Haram have destabilized communities as participants have lost either one or all the bedrocks that make up a community. This finding is consistent with previous studies which reported that losses suffered by refugees have an adverse effect on their mental wellbeing (Holmes et al., 2017; Lincoln et al. 2016; Seguin et al., 2016; Valibhoy et al., 2017). In fairness, refugees may live with losses and if not properly handled, could affect their general 
well-being and productivity (Abbott, 2016; Holmes et al., 2017; Wright et al. 2016). It was not surprising that some participants mentioned that they wished not to go back to their communities so as not to remember what they have lost.

A sudden transformation in the lives of individuals was found to impact on the wellbeing of refugees. The study reported here found that participants had become dependents on, either the generosity of third parties or members of their new communities, for their daily bread. Their lives have changed dramatically as they escaped from communities they have stayed all their lives and provided for themselves to where they had to rely on others. This finding is consistent with studies by Ager and Strand (2008), Hirani et al., (2015), Rask et al., (2016) and Wright et al., (2016) who reported that the change in environment of refugees, coupled with struggle for survival and adaptation, is one major source of stress. For instance, as reported by Reinelt et al., (2016) and Schick et al., (2016), such a turn-around is worse in the event where there is differences in culture between refugees and their new communities. Similarly, AkuaSakyiwah (2017) found that differences in language make it hard for refugees to partake in income generation activities and thus, compound their vulnerability. There are also instances where refugees had to flee immigration and security officers for fear deportation (Myhrvold \& Småstuen 2017). Although this did not emerge in this study, there are reports of brutalities melted on refugees by the Cameroonian army (Human Rights Watch, 2017). This unfortunate development may be another source of stress to refugees escaping from Boko Haram attacks and probably fleeing security officers.

This study found that communities were willing to accept participants and even perceived them as equal members of the society. It emerged that there were deliberate effort by the community to support displaced persons to resettle. Shared identity is apparently the rationale behind the communities' compliance with the principle of non-refoulement. This, according to Ager and Strand (2008), is a vital resource to facilitate the integration of refugees 
to overcome their problems while settling in new communities. This finding is inconsistent with previous studies which reported that refugees are usually not accepted in their new communities (Basheti et al., 2015; Myhrvold \& Småstuen, 2017; Shick et al., 2016; Reinelt et al., 2016). For example, Holmes et al., (2017) Joyce and Liamputtong (2017), stated that the western culture of individualism and independence makes it hard for refugees who find themselves in such environment to resettle and integrate with members of the community effectively. In some cases, they are seen as burden on public purse and competitors for limited economic opportunities and subjected to discrimination (Akua-Sakyiwa, 2017; Holmes et al., 2017; Rask et al., 2016). Their inability to socialise and see themselves as equal stakeholders in the society make it hard for them to overcome their losses and begin afresh. The reserve was found here as communities opened their arms to participants who had been displaced by insurgency. Indeed, this finding have confirmed the disparities in the experiences of refugees which Silove et al., (2017) argued, should informed service delivery to displaced persons.

Employment emerged as a major need of participants who took part in this study. While differences in culture and language of host communities and refugees has been reported as reasons explaining the inability of refugees to find jobs in advanced countries (AkuaSakyiwa, 2017; Guajardo et al., 2016; Joyce \& Liamputtong, 2017), this seems not to be the case in this study. Despite shared culture and language which apparently influenced warm reception given to participants by host communities, they were unable to engage in income generating activities. Although arguments have been made that jobs and opportunity to engage in income generating activities is the primary motive of refugees or migrant who move to developed countries (Bogic et al., 2015; Guajardo et al., 2016; Joyce \& Liamputtong, 2017), the situation in Lake Chad region is peculiar because limited economic activities have existed for many years due to communal and ethnic clashes. Thence, it was expected that refugees would have problems participating in income generation activities. This finding is consistent 
with previous studies which reported limited access to job as a common barrier faced by refugees (Ager \& Strand, 2008; Akua-Sakyiwa, 2017; Bogic et al., 2012). As found by Bogic et al., (2012, 2015) and Wright et al., (2016), inability of refugees to engage in economic activities is a major source of frustration which has impact on their psychological well-being. Perhaps, their ability to access jobs might facilitate access to other essential services such as education, health and improving on social relationships in the communities. The common identity between individuals in the Lake Char region have provided a foundation for services such as employment, to be delivered to displaced persons.

\section{Limitations of study}

Although there were participants from all the four countries, the results have to be interpreted with extreme caution. The study was limited to two (Cameroon and Nigeria) of the four countries in the Lake Chad region due to security reasons. Due to attacks and skirmishes of violence in some communities, we were advised by security officers not to cross to communities in Chad and Niger. The results may not be representative of all refugees who have been displaced in the Lake Chad region. It is important for future studies to examine the experiences and psychological well-being of refugees in the two other countries to get holistic picture of their situation. Also, the security officers determined the mode of data collection (either one-on-one interviews or focus group discussion) in both countries and this might have implications on the responses of participants. Notwithstanding, the study has given a glimpse of the living conditions of refugees who have been displaced in the Lake Chad region.

\section{Conclusion and policy implications}

This study documented the experiences of refugees in the Lake Chad region; from the perspective of eco-social model. This study has made substantial contribution to literature and 
reiterated the need for contextualisation of service delivery to individuals displaced by political insurgency. Boko Haram capitalised on lapses and diplomatic failures to operate in the Lake Chad region. The study reported here found that the insurgency have had devastating impacts on participants who took part in the study. In the first place, participants were found to have lost relatives, properties and even displaced from their homes which had implications on their psychological well-being. Also, the limited economic opportunities in the Lake Chad region denied participants access to jobs. Besides, it has been reported that Cameroon resort to force and brutalise refugees entering their territories (Human Rights Watch, 2017). All these developments have implications on the psychological well-being of victims of political violence. These findings are consistent with previous studies which reported that the experiences of refugees have adverse impact on their physical, emotional and social well-being (Abbott, 2016; Bogic et al., 2016; Holmes et al., 2017; Valibhoy et al., 2017).

Conceptually, this dynamic situation has confirmed the need for eco-social approach towards services delivery to refugees (Silove et al., 2017). Boko Haram has shown that poverty is a threat to national security and it is time governments put mechanisms in place to address this menace. The common enemy in the Lake Chad region is not only Boko Haram but also poverty and unemployment. It is, therefore, imperative for governments and humanitarian agencies to focus attention to creating economic opportunities to enhance the smooth integration of refugees. The situation in Lake Chad region is not the only peculiar situation in Africa where ethnic groups are split between two or more countries. Therefore, it is a wake-up call for governments to devise a common strategy aimed at creating economic opportunities for their citizens in order to avert future crises. In this study, the host communities seem to have provided solace to refugees by accepting them as equal members of the society and thence, facilitating their resettlement. However, economic empowerment is the missing link and it is 
high time countries in the Lake Chad region prioritise this in diplomatic dialogues on solutions to conflict and instability in the region.

\section{Reference}

Abbott, A. (2016). The mental-health crisis among migrants. Nature, 538(7624), pp. 158-160. DOI: $10.1038 / 538158 \mathrm{a}$

Ager, A., \& Strang, A. 2008. Understanding integration: A conceptual framework. Journal of refugee studies, 21, no. 2, 166-191. DOI:10.1093/jrs/fen016

Akinola, O. 2015. Boko Haram insurgency in Nigeria: Between Islamic fundamentalism, politics, and poverty. African Security, 8, no. 1, pp. 1-29. DOI: 10.1080/19392206.2015.998539

Akua-Sakyiwah B. 2017 Away From Home: Somali Women's Mediated Entry Into the United Kingdom. Journal of Immigrant \& Refugee Studies, 15, no. 1, pp. 1-17, DOI: 10.1080/15562948.2016.1151095

Angerbrandt, H. (2017). Nigeria and the Lake Chad region beyond Boko Haram. Uppsala: Nordic Africa Institute.

Basheti, I. A., Qunaibi, E. A., \& Malas, R. (2015). Psychological impact of life as refugees: A pilot study on a Syrian camp in Jordan. Tropical Journal of Pharmaceutical Research, 14(9), pp. 1695-1701. DOI: 10.4314/tjpr.v14i9.22

Bogic, M., Njoku, A., \& Priebe, S. (2015). Long-term mental health of war-refugees: a systematic literature review. BMC international health and human rights, 15(29), pp. 1-41. DOI: 10.1186/s12914-015-0064-9

Bogic, M., Ajdukovic, D., Bremner, S., Franciskovic, T., Galeazzi, G. M., Kucukalic, A., ... \& Wang, D. (2012). Factors associated with mental disorders in long-settled war refugees: refugees from the former Yugoslavia in Germany, Italy and the UK. The British Journal of Psychiatry, 200(3), pp.216-223. DOI: 10.1192/bjp.bp.110.084764

Braun, V., \& Clarke, V. 2006. Using thematic analysis in psychology. Qualitative research in Psychology, 3, no. 2, pp. 77-101. DOI: 10.1191/1478088706qp063oa

Coe, M.T. and Foley, J.A. 2001: Human and natural impacts on the water resources of the Lake Chad Basin. Journal of Geophysical Research, 106, pp. 3349-56.

Comolli, V. 2015. The Regional Problem of Boko Haram. Survival, 57, no. 4, pp. 109-117. DOI: $10.1080 / 00396338.2015 .1068560$

Feller, E., Khan, 1., Jaquemet, S., and Lecler, P. (2001). Refugee Protection: A Guide to International Refugee Law. Geneva: Inter Parliamentary Union with the Office of the United Nations High Commissioner for Refugees. http://archive.ipu.org/PDF/publications/refugee_en.pdf

Georgiadou, E., Morawa, E., \& Erim, Y. (2017). High Manifestations of Mental Distress in Arabic Asylum Seekers Accommodated in Collective Centers for Refugees in Germany. International Journal of Environmental Research and Public Health, 14(6), 612. doi:10.3390/ijerph14060612

Gray, S., \& Adeakin, I. 2015. The Evolution of Boko Haram: From Missionary Activism to Transnational Jihad and the Failure of the Nigerian Security Intelligence Agencies. African Security, 8, no. 3, pp. 185-211. DOI: 10.1080/19392206.2015.1069120

Guajardo, M. G. U., Slewa-Younan, S., Santalucia, Y., \& Jorm, A. F. (2016). Important 
considerations when providing mental health first aid to Iraqi refugees in Australia: a Delphi study. International Journal of Mental Health Systems, 10(1), 54.

DOI: $10.1186 / \mathrm{s} 13033-016-0087-1$

Hansen, W. (2015). Boko Haram: Religious Radicalism and Insurrection in Northern Nigeria. Journal of Asian and African Studies, 52(4), pp. 551-569. DOI: 10.1177/0021909615615594

Hirani, K., Payne, D., Mutch, R., \& Cherian, S. (2016). Health of adolescent refugees resettling in high-income countries. Archives of disease in childhood, 101(7), pp. 670676. http://dx.doi.org/10.1136/archdischild-2014-307221

Holmes, E. A., Ghaderi, A., Eriksson, E., Lauri, K. O., Kukacka, O. M., Mamish, M., ... \& Visser, R. M. (2017). 'I Can't Concentrate': A Feasibility Study with Young Refugees in Sweden on Developing Science-Driven Interventions for Intrusive Memories Related to Trauma. Behavioural and Cognitive Psychotherapy, 45(2), pp. 97-109. doi:10.1017/S135246581600062X

Human Rights Watch (2017). "They Forced Us Onto Trucks Like Animals." Cameroon's Mass Forced Return and Abuse of Nigerian Refugees. https://www.hrw.org/report/2017/09/27/they-forced-us-trucks-animals/cameroonsmass-forced-return-and-abuse-nigerian

Institute for Economics and Peace (2015). Measuring and Understanding The Impact of Terrorism. Global Terrorism Index. Retrieved 3 November, 2016 from IEP: www.economicsandpeace.org

Jaeger, G. (2001). On the history of the international protection of refugees. International Review of the Red Cross, 83(843), pp. 727-738. https://www.icrc.org/ara/assets/files/other/727_738_jaeger.pdf

Joyce, L., \& Liamputtong, P. 2017. Acculturation stress and social support for young refugees in regional areas. Children and Youth Services Review, 77, pp. 18-26. DOI: 10.1016/j.childyouth.2017.03.016

Lincoln, A. K., Lazarevic, V., White, M. T., \& Ellis, B. H. (2016). The impact of acculturation style and acculturative hassles on the mental health of Somali adolescent refugees. Journal of immigrant and minority health, 18(4), pp. 771-778. doi:10.1007/s10903-015-0232-y

Mbah, P., Nwangwu, C., \& Edeh, H. C. (2017). Elite politics and the emergence of boko haram insurgency in Nigeria. TRAMES: A Journal of the Humanities \& Social Sciences, 21(2). DOI: 10.3176/tr.2017.2.06

Mercy Corps, (2017). Lake Chad Basin: Mercy Corps Position Paper. https://www.mercycorps.org/sites/default/files/Lake-Chad-Basin-Mercy-CorpsResilience-Position-Paper-February2017.pdf

Myhrvold, T., \& Småstuen, M. C. (2017). The mental healthcare needs of undocumented migrants: an exploratory analysis of psychological distress and living conditions among undocumented migrants in Norway. Journal of clinical nursing, 26(5-6), pp. 825-839. DOI: $10.1111 /$ jocn. 13670

Neiland, A. and Bene, C. (2003). Sustainable development of African continental fisheries: A regional study of policy options and policy formation mechanisms for the Lake Chad Basin. University of Portsmouth and European Commission, eU-INCO Project, Final Report 48 pp.

Ngatcha, B.N. 2009: Water resources protection in the Lake Chad Basin in the changing environment. European Water 25, pp. 3-12.

Okpara, U. T., Stringer, L. C., Dougill, A. J., \& Bila, M. D. (2015). Conflicts about water in Lake Chad: Are environmental, vulnerability and security issues linked?. Progress in Development Studies, 15(4), pp. 308-325. DOI:10.1177/1464993415592738 
Opoku, M. P., Sakah, B. N., \& Alupo, B. A. (2017). The impact of Boko Haram threat on economic activities in Cameroon: perceptions of people in Yaoundé. Behavioral Sciences of Terrorism and Political Aggression, 9(3), pp. 222-237. DOI: 10.1080/19434472.2016.1231212

Onuoha, F.C. (2008). Environmental degradation, livelihood and conflict: a focus on the implications of the diminishing Lake Chad Basin for North-eastern Nigeria. African Journal on Conflict Resolution 8, pp. 1-47.

Oyewole, S. (2015). Boko Haram: Insurgency and the war against terrorism in the Lake Chad region. Strategic Analysis, 39(4), 428-432. DOI:10.1080/09700161.2015.1047227

Popovski, V., \& Maiangwa, B. (2016). Boko Haram's attacks and the people's response: A 'fourth pillar' of the responsibility to protect?. African Security Review, 25(2), pp. 159-175. DOI: 10.1080/10246029.2016.1152987

Rask, S., Suvisaari, J., Koskinen, S., Koponen, P., Mölsä, M., Lehtisalo, R., ... \& Castaneda, A. E. (2016). The ethnic gap in mental health: a population-based study of Russian, Somali and Kurdish origin migrants in Finland. Scandinavian journal of public health, 44(3), pp. 281-290. DOI: 10.1177/1403494815619256

Reinelt, T., Vasileva, M., \& Petermann, F. (2016). Refugee Children's Mental Health Problems: Beyond Posttraumatic Stress Disorder. KINDHEIT UND ENTWICKLUNG, 25(4), pp. 231-237. DOI: 10.1026/0942-5403/a000207

Schick, M., Zumwald, A., Knöpfli, B., Nickerson, A., Bryant, R. A., Schnyder, U., ... \& Morina, N. (2016). Challenging future, challenging past: The relationship of social integration and psychological impairment in traumatized refugees. European journal of psychotraumatology, 7(1), 28057. DOI: 10.3402/ejpt.v7.28057

Seguin, M., Lewis, R., Amirejibi, T., Razmadze, M., Makhashvili, N., \& Roberts, B. (2016). Our flesh is here but our soul stayed there: A qualitative study on resource loss due to war and displacement among internally-displaced women in the Republic of Georgia. Social Science \& Medicine, 150, pp. 239-247. https://doi.org/10.1016/j.socscimed.2015.12.045

Shawyer, F., Enticott, J. C., Block, A. A., Cheng, I. H., \& Meadows, G. N. (2017). The mental health status of refugees and asylum seekers attending a refugee health clinic including comparisons with a matched sample of Australian-born residents. BMC Psychiatry, 17(1), 76. DOI: 10.1186/s12888-017-1239-9

Silove, D., Ventevogel, P., \& Rees, S. (2017). The contemporary refugee crisis: an overview of mental health challenges. World Psychiatry, 16(2), pp. 130-139. DOI: 10.1002/wps.20438

UNHCR (2015). Global trends: forced displacement in 2015. http://www.unhcr.org/576408cd7.pdf

UNHCR (2014). Global trends: forced displacement in 2014. http://www.unhcr.org/556725e69.pdf

Valibhoy, M. C., Valibhoy, M. C., Szwarc, J., Szwarc, J., Kaplan, I., \& Kaplan, I. (2017). Young service users from refugee backgrounds: their perspectives on barriers to accessing Australian mental health services. International Journal of Human Rights in Healthcare, 10(1), pp. 68-80. 10.1108/IJHRH-07-2016-0010

Weeraratne, S. 2017. Theorizing the expansion of the Boko Haram insurgency in Nigeria. Terrorism and Political Violence, 29(4), 610-634. DOI: 10.1080/09546553.2015.1005742

Wright, A. M., Aldhalimi, A., Lumley, M. A., Jamil, H., Pole, N., Arnetz, J. E., \& Arnetz, B. B. (2016). Determinants of resource needs and utilization among refugees over time. Social Psychiatry and Psychiatric Epidemiology, 51(4), pp. 539-549. DOI 10.1007/s00127-015-1121-3 